\title{
Effects of hypoxia on progranulin expression in HT22 mouse hippocampal cells
}

\author{
LI LUO $^{1 *}$, LANHAI LÜ ${ }^{2 *}$, YINGHONG LU ${ }^{1}$, LIHONG ZHANG ${ }^{3}$, BOFEI LI ${ }^{1}$, \\ KAIHUA GUO $^{1}$, LIZHI CHEN ${ }^{1}$, YANG WANG ${ }^{1}$, YIJIA SHAO ${ }^{1}$ and JIE XU ${ }^{1}$ \\ ${ }^{1}$ Department of Anatomy and Neurobiology, Zhongshan School of Medicine, Sun Yat-sen University, \\ Guangzhou, Guangdong 510080; ${ }^{2}$ Guanghua School of Stomatology, Hospital of Stomatology, \\ Guangdong Provincial Key Laboratory of Stomatology, Institute of Stomatological Research, Sun Yat-sen University, \\ Guangzhou, Guangdong 510055; ${ }^{3}$ Department of Neurology, The Second Hospital of Hebei Medical University, \\ Shijiazhuang, Hebei 050000, P.R. China
}

Received June 11, 2013; Accepted January 29, 2014

DOI: $10.3892 / \mathrm{mmr} .2014 .2016$

\begin{abstract}
The present study evaluated the effect of hypoxia on the expression of progranulin in HT22 mouse hippocampal cells. To investigate progranulin (PGRN) and the alterations in its expression following hypoxia, the HT22 cells were treated with various concentrations of sodium hydrosulfite $\left(\mathrm{Na}_{2} \mathrm{~S}_{2} \mathrm{O}_{4} ; 1-20 \mathrm{mM}\right)$ for a fixed time $(6 \mathrm{~h})$ or with a fixed concentration $(5 \mathrm{mM})$ for different lengths of time $(2-10 \mathrm{~h})$. The expression of PGRN in the HT22 cells following hypoxia was analyzed by an immunocytochemistry assay and western blot analysis. The data revealed that the HT22 cells were capable of expressing PGRN. Double labeling results revealed that PGRN was able to co-localize with the neuronal markers, $\beta$ III-tubulin and doublecortin. Western blot analyses indicated that hypoxia was able to decrease the PGRN levels in a concentration-dependent manner at $6 \mathrm{~h}$, although there was a marginal increase within a shorter period. The results of this
\end{abstract}

Correspondence to: Dr Lanhai Lü, Guanghua School of Stomatology, Hospital of Stomatology, Guangdong Provincial Key Laboratory of Stomatology, Institute of Stomatological Research, Sun Yat-sen University, 56 Ling Yaun Road West, Guangzhou, Guangdong 510055, P.R. China

E-mail:1vlanhai@mail.sysu.edu.cn

Professor Jie Xu, Department of Anatomy and Neurobiology, Science Building, Zhongshan School of Medicine, Sun Yat-sen University Northern Campus, No. 74 Zhong Shan Er Road, YueXiu, Guangdong 510080, P.R. China

E-mail:xujie@mail.sysu.edu.cn

\section{${ }^{*}$ Contributed equally}

Abbreviations: PGRN, progranulin; $\mathrm{Na}_{2} \mathrm{~S}_{2} \mathrm{O}_{4}$, sodium hydrosulfite; CCK-8, cell counting kit-8; DCX, doublecortin; DMEM, Dulbecco's modified Eagle's medium; PBS, phosphate-buffered saline; TBS, Tris-buffered saline

Key words: hypoxia progranulin, HT22 cells, neural injury study revealed that hypoxic injury is capable of significantly affecting the expression of PGRN, thereby it may provide novel insights with regard to the role of PGRN in ischemic brain injury.

\section{Introduction}

Progranulin (PGRN), also known as proepithelin, acrogranin or prostate cancer cell-derived growth factor, is a growth modulating factor that has gained attention in the research of the cell cycle, wound repair, tumorigenesis, inflammation, neurodevelopment and more recently, in psychosis and neurodegeneration (1-3). PGRN is also capable of functioning as a neurotrophic factor, and its mutations in the PGRN gene are amongst the most common causes of familial frontotemporal lobar degeneration with TDP-43-positive inclusions $(4,5)$. The null and missense mutations in PGRN have also been observed in patients with clinically diagnosed Alzheimer's disease $(6,7)$, but have no major role in the genetic etiology of Parkinson's disease (8). Previous animal experiments demonstrated that PGRN was upregulated following experimental spinal cord injury and downregulated following traumatic brain injury $(9,10)$. However, few studies have examined the involvement of PGRN in cerebral ischemia (11-13).

The expression and functions of PGRN in the central nervous system are complicated. In the embryonic brain, PGRN is widely expressed and is involved in the sexual differentiation of the brain (14). In the adult brain, PGRN expression is restricted to microglia and specific neuronal populations, including pyramidal neurons in the neocortex and hippocampus, and Purkinje cells in the cerebellum (15). PGRN has been indicated to function in regulating neurite outgrowth and enhancing neuronal survival, indicating that it has neurotrophic activity (16). Hypoxia increases progranulin expression in fibroblast cultures and neuroblastoma cell lines $(9,17)$. Little is known about how hypoxia affects PGRN expression in neuronal cell lines. In the present study, the expression pattern of PGRN was examined and the alterations in PGRN expression were investigated in HT22 mouse hippocampal cells in hypoxic conditions. 


\section{Materials and methods}

Chemicals. The sheep polyclonal anti-PGRN antibody was purchased from R\&D Systems (Minneapolis, MN, USA). The rabbit polyclonal anti-doublecortin (Dcx) antibody was supplied from Cell Signaling Technology, Inc. (Danvers, MA, USA). The mouse monoclonal anti- $\beta$ III-tubulin antibody was supplied by Abcam (Hong Kong, China). The rabbit polyclonal anti- $\beta$-actin antibody was obtained from Abmart (Shanghai, China). Fluorescence-labeled secondary antibodies (goat anti-mouse (Alexa Fluor594), goat anti-rabbit (Alexa Fluor594) and donkey anti-sheep (Alexa Fluor488). were supplied from Invitrogen Life Technologies (Carlsbad, CA, USA). Sodium hydrosulfite $\left(\mathrm{Na}_{2} \mathrm{~S}_{2} \mathrm{O}_{4}\right)$ was purchased from Sigma-Aldrich (St. Louis, MO, USA).

Cell culture. The HT22 cells were a gift from Professor Jun Liu (The Second Affiliated Hospital, Sun Yat-sen University, Guangzhou, Guangdong, China). The HT22 cells were maintained in Dulbecco's modified Eagle's medium (DMEM) with $10 \%$ heat-inactivated fetal bovine serum and antibiotics (100 IU/ml penicillin and $100 \mu \mathrm{g} / \mathrm{ml}$ streptomycin) at $37^{\circ} \mathrm{C}$, with $5 \% \mathrm{CO}_{2}$, under standard conditions. Differentiated HT22 cells were grown in NeuroBasal medium (Millipore, Billerica, MA, USA) containing 1X N2 supplement for $24 \mathrm{~h}$ prior to use.

Induction of a hypoxia model. A hypoxia model was prepared as previously described (18). Hypoxia was induced in the HT22 cells by incubation with $\mathrm{Na}_{2} \mathrm{~S}_{2} \mathrm{O}_{4}$, which is able to instantly lower the partial pressure of oxygen $\left(\mathrm{PaO}_{2}\right)$ of the solutions (19). Briefly, the cells were rinsed twice with phosphate-buffered saline (PBS) solution and treated with various concentrations of $\mathrm{Na}_{2} \mathrm{~S}_{2} \mathrm{O}_{4}(1,2,5,10$ or $20 \mathrm{mM})$ for a fixed time $(6 \mathrm{~h})$ or for different lengths of time $(2,4,6,8$ or $10 \mathrm{~h})$ at a fixed concentration $(5 \mathrm{mM})$ in DMEM medium. Since $\mathrm{Na}_{2} \mathrm{~S}_{2} \mathrm{O}_{4}$ solutions are acidic, the $\mathrm{pH}$ was adjusted to 7.4 prior to the experiment by adding extra $\mathrm{NaOH}$, as described previously $(20,21)$. The control cells were maintained in normal DMEM. The cell viability was measured by optical microscopy (Leica DMI4000B, Leica, Wetzlar Germany) and a cell counting kit-8 (CCK-8; Beyotime Institute of Biotechnology, Haimen, China) according to the manufacturer's instructions. Briefly, the cells were plated onto a 96 -well plate $\left(5 \times 10^{3}\right.$ cells/ well) and were grown for $24 \mathrm{~h}$ at $37^{\circ} \mathrm{C}$ prior to being subjected to different treatments. Following the treatments, CCK- 8 solution $(10 \mu \mathrm{l})$ was added to each well of the plate. Following incubation for $1 \mathrm{~h}$ at $37^{\circ} \mathrm{C}$ in the dark, the optical density was measured at $450 \mathrm{~nm}$ using an absorbance microplate reader (BioTek Instruments, Inc., Winooski, VT, USA). The percentage viability was calculated with viability in the untreated control cells considered as $100 \%$.

Immunocytochemistry assay. The HT22 cells were seeded on poly-L-lysine and laminin pre-treated glass coverslips at a density of $1 \times 10^{5} /$ well. Following differentiation and treatment, the cells were first washed three times with PBS and fixed in $4 \%$ paraformaldehyde solution [ $4 \%$ paraformaldehyde, $0.1 \mathrm{mmol} / 1 \mathrm{CaCl}_{2}$ and $0.1 \mathrm{mmol} / 1 \mathrm{MgCl}_{2}$ (pH 7.4) in PBS] for $20 \mathrm{~min}$ at room temperature. The cells were then washed three times with PBS, permeabilized in $0.3 \%$ Triton X-100 (Beyotime Institute of Biotechnology)/PBS for $5 \mathrm{~min}$ and washed again three times with PBS. Next, the cells were blocked for $1 \mathrm{~h}$ at room temperature using 10\% normal goat serum to reduce non-specific binding. The cells were then incubated with different primary antibodies (PGRN, 1:800; $\beta$ III-tubulin, 1:1,000; NeuN, 1:1000; and Dcx, 1:1,000) in PBS at $4^{\circ} \mathrm{C}$ overnight. Following sufficient washing, the cells were incubated with the appropriate fluorescence-conjugated secondary antibodies for $1 \mathrm{~h}$ at $37^{\circ} \mathrm{C}$. Finally, the nuclei were stained with Hoechst 33342, and the coverslips were mounted on slides with FluorSave Reagent (Beyotime Institute of Biotechnology). The morphologies were captured under a fluorescence microscope (BX51; Olympus, Tokyo, Japan).

Western blot analysis. Western blotting was used to semi-quantitatively detect the expression of PGRN following hypoxia treatment as aforementioned. The expression of $\beta$-actin was considered as an internal control. For the western blot analysis, the HT22 cells were seeded onto $60-\mathrm{mm}$ dishes at a density of $2 \times 10^{5}$ cells/dish. The following day, the cells were treated with $\mathrm{Na}_{2} \mathrm{~S}_{2} \mathrm{O}_{4}$ at different concentrations and time intervals. Following the treatment, the cells were rinsed three times with PBS, lysed with radioimmunoprecipitation assay lysis buffer (Beyotime Institute of Biotechnology) and incubated on ice for $30 \mathrm{~min}$. The lysates were then centrifuged at $12,000 \mathrm{x} \mathrm{g}$ for $20 \mathrm{~min}$ at $4^{\circ} \mathrm{C}$ and the supernatant extracts were quantified for the total protein using a Bicinchoninic Acid Protein Assay kit (Beyotime Institute of Biotechnology) with bovine serum albumin as the standard. Aliquots from each protein lysate sample were separated in $10 \%$ sodium dodecyl sulfate-polyacrylamide gel electrophoresis and transferred to a poly-vinylidene fluoride membrane (Millipore, Schwalbach, Germany). The membrane was blocked with blocking buffer [Tris-buffered saline (TBS) and 5\% skimmed milk] for $1 \mathrm{~h}$ at room temperature and incubated overnight in the presence of the primary antibodies against PGRN $(1: 8,000)$ and $\beta$-actin $(1: 10,000)$, at $4^{\circ} \mathrm{C}$. The membrane was washed three times with TBS containing $0.05 \%$ Tween 20 (TBST) and subsequently reacted with the corresponding secondary antibody for $1 \mathrm{~h}$ at room temperature. Following thorough washing with TBST, the immunoreactive bands were developed using enhanced chemiluminescence detection reagents (Millipore). The optical density of the bands on the films was analyzed using imaging software (ImageQuant Las4000; GE Healthcare, Pittsburgh, PA, USA).

Statistical analysis. The results are expressed as the mean \pm standard error of the mean from at least three independent experiments. A statistical evaluation was performed with a one-way analysis of variance followed by Duncan's multiple range test, which was used to compare the control and treated groups. $\mathrm{P}<0.05$ was used to indicate a statistically significant difference.

\section{Results}

Reproduction of the hypoxia model. As shown in Fig. 1, there was a notable decrease in the cell number and many cells lost neurites. Following exposure to $\mathrm{Na}_{2} \mathrm{~S}_{2} \mathrm{O}_{4}$, the majority of the 

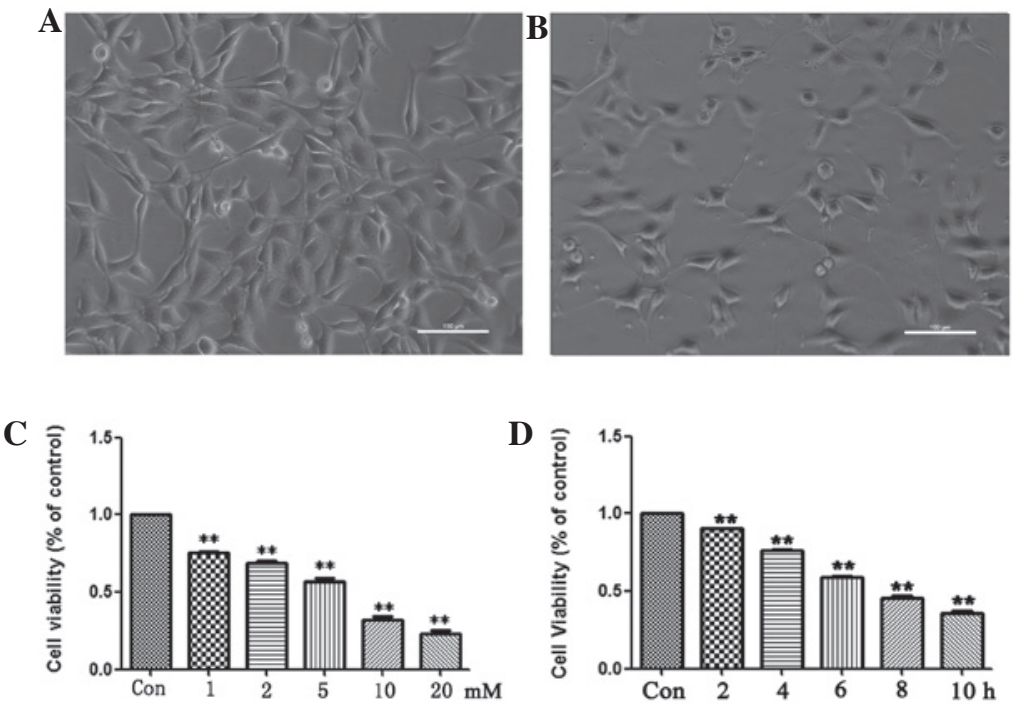

Figure 1. Morphological changes and cell survival of HT22 cells following treatment with sodium hydrosulfite $\left(\mathrm{Na}_{2} \mathrm{~S}_{2} \mathrm{O}_{4}\right)$. (A) Control group and (B) hypoxia $(5 \mathrm{mM}, 6 \mathrm{~h}$ ) group (magnification $\mathrm{x} 200)$. The cell viability was measured by a cell counting kit-8 (CCK-8) assay. Cells were exposed to various concentrations of $\mathrm{Na}_{2} \mathrm{~S}_{2} \mathrm{O}_{4}(1,2,5,10$ or $20 \mathrm{mM})$ for a fixed time $(6 \mathrm{~h})$ or for different lengths of time $(2,4,6,8$ or $10 \mathrm{~h})$ with a fixed concentration $(5 \mathrm{mM})$ in Dulbecco's modified Eagle's medium, and then evaluated by the CCK-8 assay. (C) HT22 cells were exposed to various concentrations of $\mathrm{Na}_{2} \mathrm{~S}_{2} \mathrm{O}_{4}$ for 6 h; the cell viability was decreased in a statistically significant dose-dependent manner following hypoxia compared with the control group $\left({ }^{* * *} \mathrm{P}<0.01\right.$, compared with the control). (D) HT22 cells were treated with $5 \mathrm{mM} \mathrm{Na}_{2} \mathrm{~S}_{2} \mathrm{O}_{4}$ at different time points; the cell viability was decreased in a statistically significant time-dependent manner following hypoxia compared with the control group ${ }^{* * *} \mathrm{P}<0.01$ compared with the control).

cells exhibited a round shape and a few were lysed or replaced by cell debris. Following incubation of the cells with $\mathrm{Na}_{2} \mathrm{~S}_{2} \mathrm{O}_{4}$, the cell viability was determined by CCK- 8 . The results revealed that the cell activity following hypoxia treatment was much lower than that of the untreated cells at all the concentrations and time-points, and the cell viability was decreased in a statistically significant dose- and time-dependent manner following hypoxia compared with the control group (Fig. 1C and D). The results also indicated that the aforementioned methods may be used for the successful reproduction of a hypoxia model.

Immunocytochemistry assay results. The immunocytochemical experiments demonstrated that the HT22 cells and hypoxia-treated HT22 cells were capable of expressing PGRN (Figs. 2 and 3); the present data revealed that the HT22 cells had high levels of PGRN in the cytoplasm and the neurites, particularly around the nuclear periphery. Double labeling results revealed that PGRN was able to co-localize with neuronal markers, $\beta$ III-tubulin and Dcx (Fig. 2).

Western blot analysis. The expression of PGRN was determined by western blot analysis (Fig. 4A and B). Western blot analysis revealed that a low concentration $(1 \mathrm{mM})$ for a long time $(6 \mathrm{~h})$ and a high concentration $(5 \mathrm{mM})$ for a short time ( $2 \mathrm{~h}$ ) had no effect on the PGRN levels, whereas higher concentrations $(2-20 \mathrm{mM})$ of $\mathrm{Na}_{2} \mathrm{~S}_{2} \mathrm{O}_{4}$ were capable of decreasing the expression of PGRN in a concentration-dependent manner at $6 \mathrm{~h}$ of incubation $(\mathrm{P}<0.05)$. PGRN expression was markedly increased following exposure to $5 \mathrm{mM} \mathrm{Na}_{2} \mathrm{~S}_{2} \mathrm{O}_{4}$ for $4 \mathrm{~h}(\mathrm{P}<0.05)$, but at the same concentration of $\mathrm{Na}_{2} \mathrm{~S}_{2} \mathrm{O}_{4}$ the expression of PGRN was decreased in a time-dependent manner during $6-10 \mathrm{~h}$ of incubation $(\mathrm{P}<0.05)$ (Fig. 4C and D).

\section{Discussion}

Stroke is a major cause of mortality from cerebral ischemia. Cerebral ischemia leads to severe neuronal cell damage and induces disruption of neuronal function. Hypoxia may be used as a representative cell model of cerebral ischemic injury by inducing a number of spatially and temporally regulated intracellular responses, ranging from reduced channel activity to altered gene expression $(22,23)$. To evaluate a possible role for PGRN in neurodegeneration, the changes in PGRN expression were investigated in the present study following exposure to hypoxic stimuli in vitro. The study demonstrated that PGRN was abundantly expressed in HT22 mouse hippocampal cells. In our present study, the changes of PGRN expression after hypoxia were first evaluated.

The present study demonstrated that the cell survival rate was decreased significantly and that the majority of the cells lost neurites following treatment with $\mathrm{Na}_{2} \mathrm{~S}_{2} \mathrm{O}_{4}$ compared with the control. Different concentrations (1-20 mM) of $\mathrm{Na}_{2} \mathrm{~S}_{2} \mathrm{O}_{4}$ used for incubation for $6 \mathrm{~h}$ and $5 \mathrm{mM} \mathrm{Na}_{2} \mathrm{~S}_{2} \mathrm{O}_{4}$ used for different lengths of time (2-10 h) significantly affected cell viability, indicating that $\mathrm{Na}_{2} \mathrm{~S}_{2} \mathrm{O}_{4}$ had remarkable toxicity on the HT22 cells. It has been reported that PGRN is a neurotropic factor that is able to regulate neurite outgrowth and enhance neuronal survival (16). Therefore, the loss of neuritis in HT22 cells may be associated with the low expression of PGRN.

PGRN is expressed in the placenta, epidermis, microvasculature and brain during murine development (24). In the central nervous system, PGRN may be expressed in neurons and microglia, but not in astrocytes and oligodendrocytes. PGRN expression in neurons increases with cell maturation, whereas expression in microglia depends on the cells' state of activation, being specifically upregulated in microglia in response to exci- 

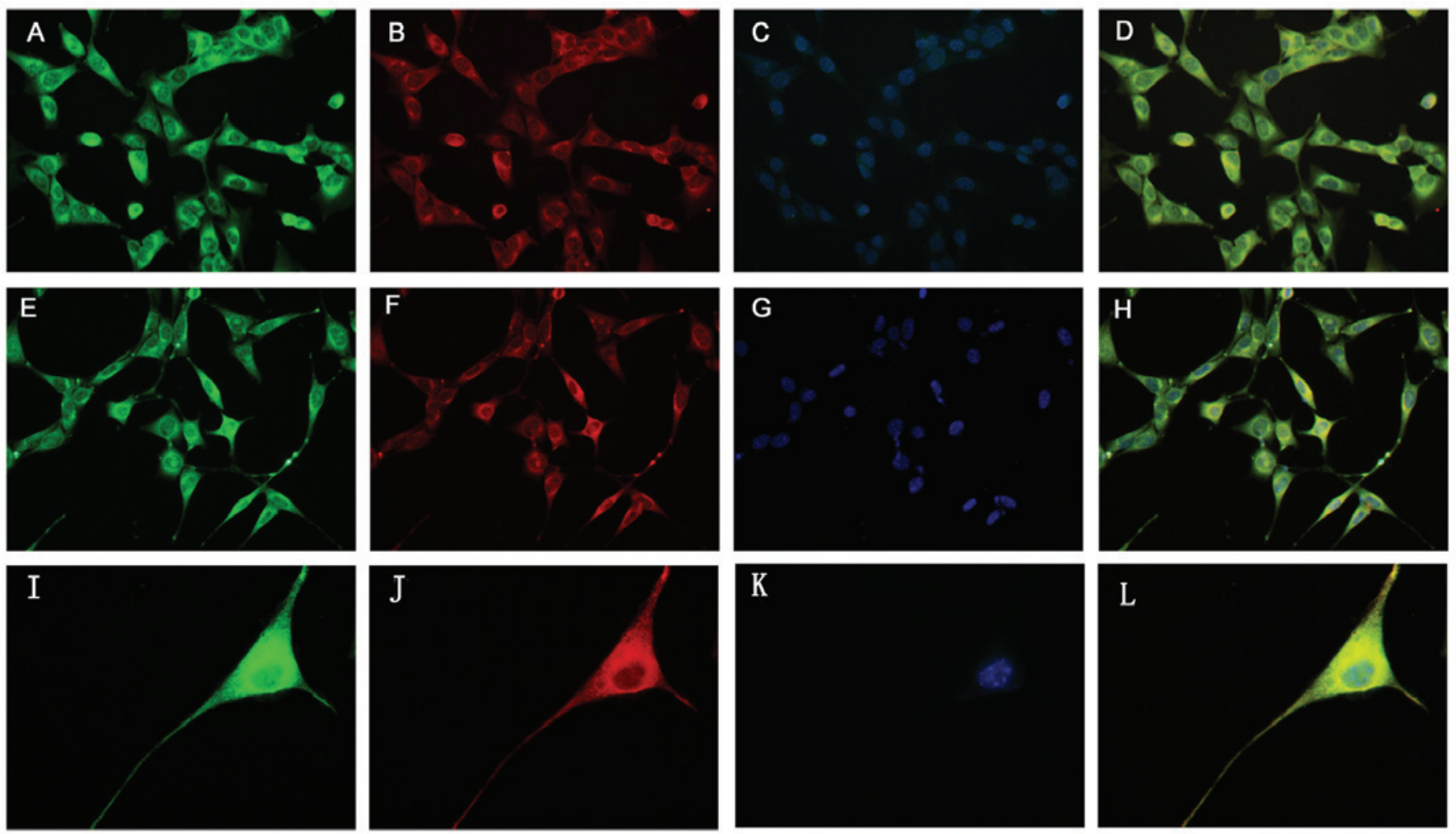

Figure 2. Identification of PGRN expression in HT22 cells by immunocytochemistry. (A-D) Expression of PGRN in HT22 cells with various neuron markers including $\beta$ III-tubulin and Dcx. PGRN (A, green) was expressed in tubulin ${ }^{+}$neurons (B, red, magnification, x400). (E-H) PGRN (E, green) was expressed in Dcx ${ }^{+}$neurons (F, red, magnification, $\mathrm{x} 400$ ). (I-L) Immunocytochemical results showed that PGRN (I, green) expression exhibited marked cytoplasm and neurite staining for PGRN, particularly nuclear periphery in HT22 cells (J, red, tubulin', magnification, x1,000). (C, G, K) Cell nuclei were visualized after DNA staining with Hoechst 33342. (D, H, L) Co-expression of PGRN in HT22 cells with different neuron markers. PGRN, progranulin.
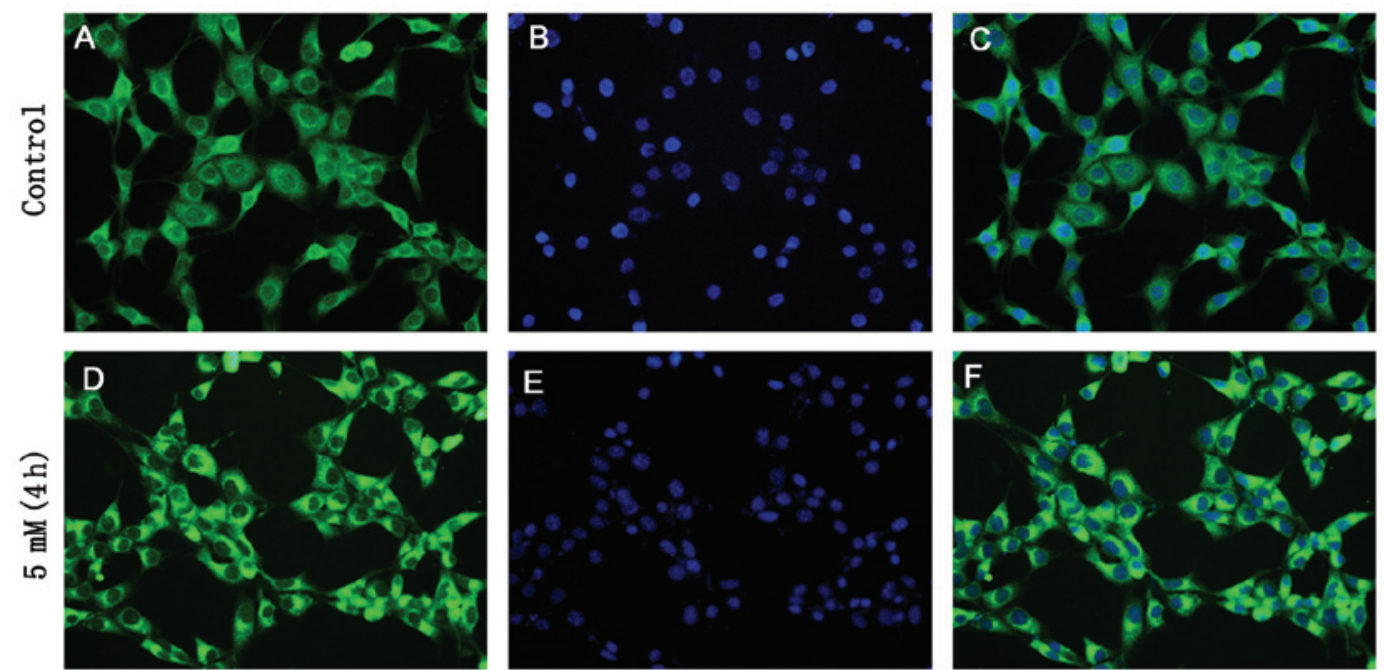

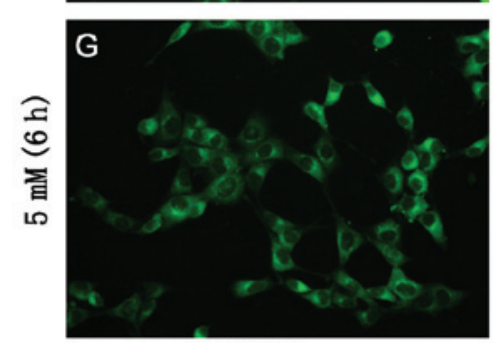

PGRN

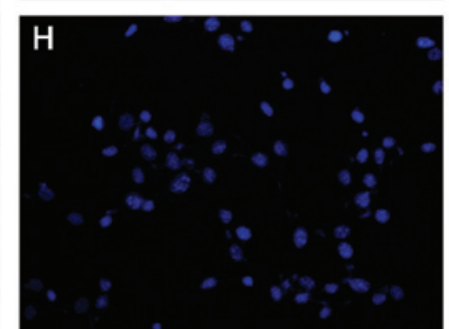

Hoechst

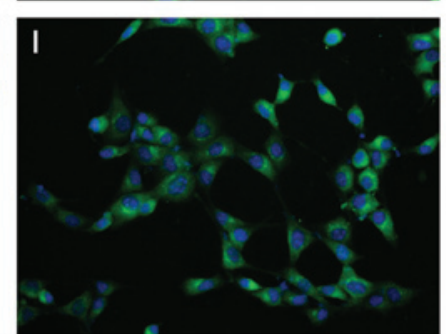

Merge

Figure 3. PGRN expression in HT22 cells and sodium hydrosulfite $\left(\mathrm{Na}_{2} \mathrm{~S}_{2} \mathrm{O}_{4}\right.$ )-treated HT22 cells. (A, D and G) PGRN expression (green) in the control, $5 \mathrm{mM}(4 \mathrm{~h})$ and $5 \mathrm{mM}(6 \mathrm{~h})$ groups, respectively. (B, E and H) The cell nuclei were stained with Hoechst 33342 (blue). (C, F, I) Merged staining images (magnification, x400). PGRN, progranulin. 
A

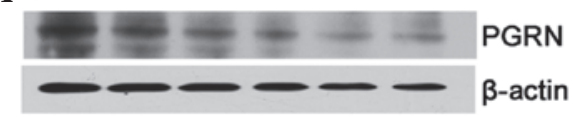

C

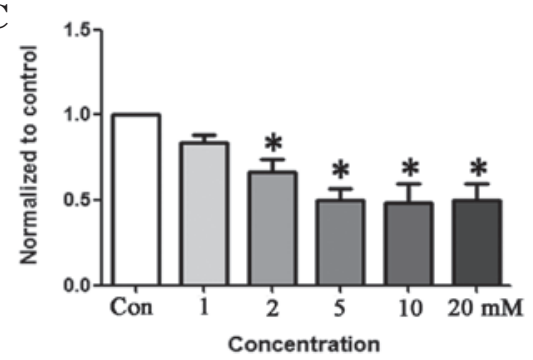

B

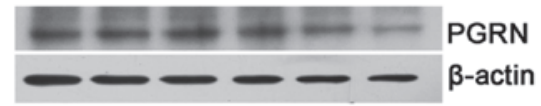

D

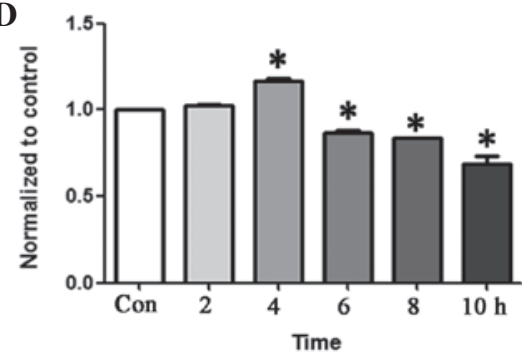

Figure 4. Progranulin (PGRN) expression by western blot analysis. (A) The PGRN expression levels in the HT22 cells following exposure to various concentrations of sodium hydrosulfate $\left(\mathrm{Na}_{2} \mathrm{~S}_{2} \mathrm{O}_{4} ; 1,2,5,10\right.$ or $\left.20 \mathrm{mM}\right)$ for a fixed time $(6 \mathrm{~h})$. (B) The PGRN expression level after the HT22 cells were exposed for different lengths of time $(2,4,6,8$ or $10 \mathrm{~h})$ to a fixed concentration $(5 \mathrm{mM})$ of $\mathrm{Na}_{2} \mathrm{~S}_{2} \mathrm{O}_{4}$. (C) Western blot analysis demonstrating that $1 \mathrm{mM}$ $\mathrm{Na}_{2} \mathrm{~S}_{2} \mathrm{O}_{4}$ had no effect on the PGRN levels at $6 \mathrm{~h}$ of incubation, whereas higher concentrations $(2,5,10$ or $20 \mathrm{mM})$ of $\mathrm{Na}_{2} \mathrm{~S}_{2} \mathrm{O}_{4}$ decreased the expression of PGRN in a concentration-dependent manner ( $\mathrm{P}<0.05$ compared with the control). (D) Following 2 h of incubation with 5 mM Na $\mathrm{S}_{2} \mathrm{O}_{4}$, no effect was shown on the PGRN levels. PGRN expression was markedly increased ( $\mathrm{P}<0.05$ compared with the control) following $4 \mathrm{~h}$ of exposure to 5 mM Na $\mathrm{S}_{2} \mathrm{O}_{4}$; however, $5 \mathrm{mM} \mathrm{Na} \mathrm{S}_{2} \mathrm{O}_{4}$ decreased the expression of PGRN in a time-dependent manner during 6-10 h of incubation (P<0.05 compared with the control). ${ }^{*} \mathrm{P}<0.05$ vs. control.

totoxic injury (25). However, upregulation of PGRN is a marker of the microglial response that occurs with progression in motor neuron diseases (26). The roles of microglial and neuronal progranulin in neurological disease require addressing. The present study characterized PGRN in the widely used HT22 hippocampal neuronal cell line, a sub-line derived from parent HT4 cells that were originally immortalized from a primary mouse hippocampal neuronal culture (27). An immunochemical characterization of the HT22 cells revealed that the cells became positively stained with essential neuron markers, including $\beta$ III-tubulin and Dcx. The data from the present study also indicated that PGRN was mainly expressed within the cell bodies and in the axons of the HT22 cells. Previous studies have demonstrated that PGRN is expressed in motor neurons, neuroblastoma cell lines and fibroblasts $(9,17,28)$. Certain studies demonstrated that extracellular PGRN may protect cortical neurons from toxic insults induced by glutamate excitotoxicity and oxidative stress (29). Therefore, the PGRN protein may be used therapeutically in the field of neurodegenerative diseases.

Cells of different origins express PGRN in different ways (28). Previous studies have demonstrated that hypoxia (1\% oxygen) and acidosis may increase PGRN expression in fibroblasts (17). Hypoxia also induces the upregulation of progranulin in neuroblastoma cell lines (SK-N-BE, SK-N-SH and SH-SY5Y), however PGRN is not altered following hydroperoxide-induced oxidative stress (23). Previous studies have indicated that PGRN acts as an endogenous neuroprotectant with anti-apoptotic and anti-inflammatory properties in focal cerebral ischemic mice (30). PGRN expression is upregulated following spinal contusion in mice (9), but traumatic brain injury may increase the risk of frontotemporal dementia through reduced PGRN (31). To clarify the role of PGRN in neurodegeneration, the modulation of PGRN expression was evaluated in the present study following exposure to hypoxia induced by incubation with $\mathrm{Na}_{2} \mathrm{~S}_{2} \mathrm{O}_{4}$. The results of the western blot analysis demonstrated that PGRN expression was upregulated within $4 \mathrm{~h}$ of exposure to $5 \mathrm{mM} \mathrm{Na}_{2} \mathrm{~S}_{2} \mathrm{O}_{4}$, which indicated that within a short $\mathrm{Na}_{2} \mathrm{~S}_{2} \mathrm{O}_{4}$ incubation time, PGRN expression was induced. We hypothesize that PGRN is part of a neuronal stress response to apoptosis that occurs within a short time period. The results also demonstrated that PGRN expression was markedly downregulated in a time-dependent manner during 6-10 h of incubation, which indicated that with the length of treated time $\mathrm{Na}_{2} \mathrm{~S}_{2} \mathrm{O}_{4}$ inhibited PGRN expression. In addition, higher concentrations of $\mathrm{Na}_{2} \mathrm{~S}_{2} \mathrm{O}_{4}$ (2-20 mM) were able to significantly downregulate PGRN expression in a concentration-dependent manner following $6 \mathrm{~h}$ of incubation, indicating that downregulated PGRN expression may be correlated with a lower cell viability. The changes in PGRN expression induced by hypoxia may depend on the duration and severity of hypoxia, therefore the PGRN expression pattern may be associated with different cell types and their environmental stimuli, including hypoxia and oxidative stress.

In conclusion, the results of the present study demonstrated that PGRN is abundantly expressed in HT22 cells. The data indicated that hypoxia may induce cell death by exposure to $\mathrm{Na}_{2} \mathrm{~S}_{2} \mathrm{O}_{4}$ in HT22 cells. The effects of hypoxia on PGRN expression in the HT22 cells were also described for the first time. This study presented a link between PGRN and hypoxic injury. However, the potential mechanisms of PGRN in ischemic brain injury should be investigated further.

Hypoxic injury may significantly affect the expression of PGRN, thereby providing novel insights with regard to the role of PGRN in ischemic brain injury.

\section{Acknowledgements}

This study was supported by The National Natural Science Foundation of China for Youth (grant no. 81000562), the National Innovation Experiment Program for University Students (grant no. 101055827) and the Medical Scientific Research Foundation of Guangdong Province, China (grant no. B2010068). 


\section{References}

1. De Muynck L and Van Damme P: Cellular effects of progranulin in health and disease. J Mol Neurosci 45: 549-560, 2011.

2. He Z and Bateman A: Progranulin (granulin-epithelin precursor, PC-cell-derived growth factor, acrogranin) mediates tissue repair and tumorigenesis. J Mol Med (Berl) 10: 600-612, 2003.

3. Al-Ayadhi LY and Mostafa GA: Low plasma progranulin levels in children with autism. J Neuroinflammation 8: 111, 2011.

4. Baker M, Mackenzie IR, Pickering-Brown SM, Gass J, Rademakers R, Lindholm C, et al: Mutations in progranulin cause tau-negative frontotemporal dementia linked to chromosome 17. Nature 442: 916-919, 2006

5. Neumann M, Sampathu DM, Kwong LK, Truax AC, Micsenyi MC, Chou TT, et al: Ubiquitinated TDP-43 in frontotemporal lobar degeneration and amyotrophic lateral sclerosis. Science 314: 130-133, 2006.

6. Sleegers K, Brouwers N and Van Broeckhoven C: Role of progranulin as a biomarker for Alzheimer's disease. Biomark Med 4: 37-50, 2010.

7. Brouwers N, Sleegers K, Engelborghs S, Maurer-Stroh S, Gijselinck I, van derZee J, et al: Genetic variability in progranulin contributes to risk for clinically diagnosed Alzheimer disease. Neurology 71: 656-664, 2008.

8. Nuytemans K, Pals P, Sleegers K, Engelborghs S, Corsmit E, Peeters K, et al: Progranulin variability has no major role in Parkinson disease genetic etiology. Neurology 71: 1147-1151, 2008.

9. Naphade SB, Kigerl KA, Jakeman LB, Kostyk SK, Popovich PG and Kuret J: Progranulin expression is upregulated after spinal contusion in mice. Acta Neuropathol 119: 123-133, 2010.

10. Matzilevich DA, Rall JM, Moore AN, Grill RJ and Dash PK: High-density microarray analysis of hippocampal gene expression following experimental brain injury. J Neurosci Res 67: 646-663, 2002.

11. Egashira Y, Suzuki Y, Azuma Y, Takagi T, Mishiro K, Sugitani S, Tsuruma K, Shimazawa M, Yoshimura S, Kashimata M, Iwama $\mathrm{T}$ and Hara $\mathrm{H}$ : The growth factor progranulin attenuates neuronal injury induced by cerebral ischemia-reperfusion through the suppression of neutrophil recruitment. J Neuroinflammation 10 : $105,2013$.

12. Jackman K, Kahles T, Lane D, Garcia-Bonilla L, Abe T, Capone C, Hochrainer K, Voss H, Zhou P, Ding A, Anrather J and Iadecola C: Progranulin deficiency promotes post-ischemic blood-brain barrier disruption. J Neurosci 33: 19579-19589, 2013.

13. Tao J, Ji F, Wang F, Liu B and Zhu Y: Neuroprotective effects of progranulin in ischemic mice. Brain Res 1436: 130-136, 2012.

14. Matsuwaki T, Asakura R, Suzuki M, Yamanouchi K and Nishihara M: Age-dependent changes in progranulin expression in the mouse brain. J Reprod Dev 57: 113-119, 2011.

15. Daniel R, He Z, Carmichael KP, Halper J and Bateman A: Cellular localization of gene expression for progranulin. J Histochem Cytochem 48: 999-1009, 2000.
16. Van Damme P, Van Hoecke A, Lambrechts D, Vanacker P, Bogaert E, van Swieten J, et al: Progranulin functions as a neurotrophic factor to regulate neurite outgrowth and enhance neuronal survival. J Cell Biol 181: 37-41, 2008.

17. Guerra RR, Kriazhev L, Hernandez-Blazquez FJ and Bateman A: Progranulin is a stress-response factor in fibroblasts subjected to hypoxia and acidosis. Growth Factors 25: 280-285, 2007.

18. Zhang XQ and Eyzaguirre C: Effects of hypoxia induced by $\mathrm{Na}_{2} \mathrm{~S}_{2} \mathrm{O}_{4}$ on intracellular calcium and resting potential of mouse glomus cells. Brain Res 818: 118-126, 1999.

19. Lawson WH Jr, Holland RA and Forster RE: Effect of temperature on deoxygenation rate of human red cells. J Appl Physiol 20: 912-918, 1965.

20. Abudara V and Eyzaguirre C: Modulation of junctional conductance between rat carotid body glomus cells by hypoxia, cAMP and acidity. Brain Res 792: 114-125, 1998 .

21. Pang L and Eyzaguirre C: Hypoxia affects differently the intracellular $\mathrm{pH}$ of clustered and isolated glomus cells of the rat carotid body. Brain Res 623: 349-355, 1993.

22. Meloni BP, Meade AJ, Kitikomolsuk D and Knuckey NW: Characterisation of neuronal cell death in acute and delayed in vitro ischemia (oxygen-glucose deprivation) models. J Neurosci Methods 195: 67-74, 2011.

23. Piscopo P, Rivabene R, Adduci A, Mallozzi C, Malvezzi-Campeggi L, Crestini A and Confaloni A: Hypoxia induces up-regulation of progranulin in neuroblastoma cell lines. Neurochem Int 57: 893-898, 2010.

24. Daniel R, Daniels E, He Z and Bateman A: Progranulin (acrogranin/PC cell-derived growth factor/granulin-epithelin precursor) is expressed in the placenta, epidermis, microvasculature, and brain during murine development. Dev Dyn 227: 593-559, 2003.

25. Petkau TL, Neal SJ, Orban PC, MacDonald JL, Hill AM, Lu G, et al: Progranulin expression in the developing and adult murine brain. J Comp Neurol 518: 3931-3947, 2010.

26. Philips T, De Muynck L, Thu HN, Weynants B, Vanacker P, Dhondt J, et al: Microglial upregulation of progranulin as a marker of motor neuron degeneration. J Neuropathol Exp Neurol 69: 1191-1200, 2010.

27. Liu J, Li L and Suo WZ: HT22 hippocampal neuronal cell line possesses functional cholinergic properties. Life Sci 84: 267-271, 2009.

28. Ryan CL, Baranowski DC, Chitramuthu BP, Malik S, Li Z, Cao M, et al: Progranulin is expressed within motor neurons and promotes neuronal cell survival. BMC Neurosci 10: 130, 2009.

29. Xu J, Xilouri M, Bruban J, Shioi J, Shao Z, Papazoglou I, et al: Extracellular progranulin protects cortical neurons from toxic insults by activating survival signaling. Neurobiol Aging 32: 2326.e5-2326.e16, 2011

30. Tao J, Ji F, Wang F, Liu B and Zhu Y: Neuroprotective effects of progranulin in ischemic mice. Brain Res 1436: 130-136, 2012.

31. Jawaid A, Rademakers R, Kass JS, Kalkonde Y and Schulz PE: Traumatic brain injury may increase the risk for frontotemporal dementia through reduced progranulin. Neurodegener Dis 6: 219-220, 2009 